\title{
The cpcB-cpcA locus as a tool for the genetic characterization of the genus Arthrospira (Cyanobacteria) : evidence for horizontal transfer
}

${ }^{1}$ University of Geneva, Conservatoire et Jardin Botaniques, Impératrice 1, $\mathrm{CH}-1292$ Chambésy, Switzerland

${ }^{2}$ Antenna Technologie, rue de Neuchâtel 29, CH-1201 Genève, Switzerland

\author{
Jean-François Manen ${ }^{1}$ and Jacques Falquet ${ }^{2}$ \\ Author for correspondence: Jean-François Manen. Tel: +4122418 5125. Fax: +41224185101. \\ e-mail:manen@cjb.ville-ge.ch
}

To investigate the genetic diversity of the genus Arthrospira and to compare it with other cyanobacteria, sequences of $670 \mathrm{nt}$ from the phycocyanin operon were determined for $\mathbf{2 3}$ natural, cultivated or commercial strains of Arthrospira and compared with sequences from 20 other non-Arthrospira cyanobacterial strains. The sequenced DNA fragment comprises the last $255 \mathrm{nt}$ of $\angle P C B$, the $с$ CPB-CPCA spacer and the first $304 \mathrm{nt}$ of $C P C A$. The resulting phylogenetic tree confirms that the genus Arthrospira is not related to Spirulina. So far, cpcB-cpcA data suggest that the closest relative of Arthrospira is Planktothrix. Based on this locus, the genus Arthrospira consists of three genetically clustered lineages. However, the distribution of nucleotide substitutions indicates that these three lineages are not the result of a simple cladogenesis characterized by the accumulation of independent substitutions. Instead, the observed clustering is the result of horizontal transfers of blocks of sequences. Analysis of the distribution of substitutions in the sequenced fragment indicates a point of intragenic recombination close to the stop codon of $\mathrm{CpCB}$. The capacity of exchange of genetic material among strains probably explains why morphology and geographical origin do not correlate with the сPCB-cpcA clusters. Nevertheless, this study shows for the first time that the genus Arthrospira, represented here by cultivated and wild specimens, is clearly monophyletic. Moreover, the cpcB-cpcA DNA fragment, comprising both highly and moderately variable regions, allows (1) a strict differentiation of the taxon Arthrospira from other cyanobacteria (using the coding regions only) and (2) the study of relationships inside Arthrospira (using both the coding and non-coding regions).

Keywords: Arthrospira, $c p c B-c p c A$, horizontal transfer, molecular phylogeny

\section{INTRODUCTION}

Arthrospira is an inexpensive, high quality nutritional supplement that has an annual industrial production reaching several hundreds tons worldwide (Ciferri \& Tiboni, 1985; Belay et al., 1993; Fox, 1996). This organism lives in warm lakes with high carbonate content and high $\mathrm{pH}$. The main purpose of this work is to clarify the diversity of natural, cultivated and

Micrographs showing the different morphologies observed among Arthrospira strains are available as supplementary data in IJSEM Online (http://ijs.sgmjournals.org). commercial strains of Arthrospira using sequence data from a highly variable DNA fragment. To define and delimit the genus Arthrospira, this study includes other cyanobacteria. A second goal of this study is to identify specific molecular markers to fingerprint different strains of Arthrospira and to develop tools for species and strain identification.

Originating from the taxonomic treatise of cyanobacteria of Geitler (1932), confusion exists between the genera Spirulina and Arthrospira. In fact, these two genera are only distantly related (Guglielmi et al., 1993; Nelissen et al., 1994). In the so-called 'Spirulina' biotechnology field, putative species of Arthrospira 
Table 1. List of strains analysed

\begin{tabular}{|c|c|c|c|}
\hline Name & Origin* & Provided by : $\uparrow$ & Accession no. \\
\hline Arthrospira platensis & $?$ & $?$ & Y09074 \\
\hline Arthrospira sp. Paracas P2 & Peru (w) & G. Planchon, 1995 & AJ401166 \\
\hline Arthrospira sp. BU1 & Burma (w) & G. Planchon, 1995 & AJ401167 \\
\hline Arthrospira sp. Maxima & $\operatorname{Mexico}(w)$ & F. Ayala, 1997 & AJ401168 \\
\hline Arthrospira sp. M1 & Chad/Spain (c) & IMADE SA, 1996 & AJ401169 \\
\hline Arthrospira sp. Paracas P0 & Peru (w) & A. Prior, 1996 & AJ401110 \\
\hline Arthrospira sp. ThD & ?/Switzerland (c) & J.-B. Menut, 1998 & AJ401111 \\
\hline Arthrospira sp. Titi & Peru (w) & R. Fox, 1996 & AJ401112 \\
\hline Arthrospira sp. M2 & Chad (w) & M. Tredicci, 1995 & AJ401113 \\
\hline Arthrospira sp. Fv-8 & $? / \mathrm{USA}(\mathrm{c})$ & Earth Raise Co., 1997 & AJ401114 \\
\hline Arthrospira sp. Paracas GE98 & Peru/Switzerland (c) & J. Falquet, 1998 & AJ401115 \\
\hline Arthrospira sp. Dihé & Chad (w) & Louis Bergier Int., 1998 & AJ401116 \\
\hline Arthrospira sp. Lonar-LoH7 & India/France $(c)$ & J.-P. Jourdan, 1997 & AJ401117 \\
\hline Arthrospira platensis $\mathrm{PCC} 7345^{\mathrm{T}}$ & California, USA (w) & PCC $7345^{\mathrm{T}}$ & AJ401118 \\
\hline Arthrospira sp. PK & ?/China (c) & Sea Source Corp., 1997 & AJ401119 \\
\hline Arthrospira sp. Mad & India (c) & Antenna Trust, 1998 & AJ401120 \\
\hline Arthrospira sp. BU2 & Burma (w) & G. Planchon, 1995 & AJ401121 \\
\hline Arthrospira sp. Mix & India/France (c) & J.-P. Jourdan, 1997 & AJ401122 \\
\hline Arthrospira sp. Sun§ & India $(c)$ & N. Sundaram, 1995 & AJ401123 \\
\hline Arthrospira sp. Nord Geitl & ?/Ukraine (c) & L. Kovechnikov, 1999 & AJ401124 \\
\hline Arthrospira sp. Sark & ?/Switzerland (c) & Arkogélules spiruline, 1999 & AJ310555 \\
\hline Arthrospira sp. Paracas E2 & Peru/Ecuador (c) & Biorigine SA, 2000 & AJ310553 \\
\hline Arthrospira sp. E1 & $? /$ Ecuador (c) & Biorigine SA, 2000 & AJ310554 \\
\hline Oscillatoria sancta & & PCC $7515^{\mathrm{T}}$ & AJ401125 \\
\hline Oscillatoria acuminata & & PCC $6304^{\mathrm{T}}$ & AJ401126 \\
\hline Lyngbya aestuarii & & PCC $7419^{\mathrm{T}}$ & AJ401127 \\
\hline Spirulina major & & PCC $6313^{\mathrm{T}}$ & AJ401128 \\
\hline Microcystis aeruginosa & & & AJ003181 \\
\hline Fischerella sp. & & & M75599 \\
\hline Anabaena sp. & & PCC 7120 & X05239 \\
\hline Nodularia spumigena & & & AF101444 \\
\hline Synechococcus elongatus & & & D13173 \\
\hline Synechocystis sp. & & PCC 9413 & AF068771 \\
\hline Pseudanabaena sp. & & PCC 7409 & M99426 \\
\hline Calothrix sp. & & PCC 7601 & M36276 \\
\hline Fremyella diplosiphon & & & X07012 \\
\hline Synechocystis sp. & & PCC 6803 & U34930 \\
\hline Chroococcus dispersus & & & AJ003184 \\
\hline Synechococcus sp. & & PCC 7002 & K02660 \\
\hline Synechococcus sp. & & & X59809 \\
\hline Synechococcus sp. & & PCC 7942 & AB008546 \\
\hline Synechococcus sp. & & PCC 6301 & M94218 \\
\hline Planktothrix rubescens & & & AJ131820 \\
\hline Cyanidium caldarium & & & $\mathrm{S} 77125$ \\
\hline Aglaothamnion neglectum & & & Z11906 \\
\hline Rhodella violacea & & & Z48165 \\
\hline
\end{tabular}

* w, Wild; c, cultivated. Where two countries are given, the first indicates the origin of the strain and the second indicates where it was cultivated;?, unknown.

$\dagger$ PCC, Pasteur Culture Collection.

$\$$ Sequences determined in this study are indicated in bold.

$\S$ Upon microscopic examination, this sample was found to be morphologically different from other known Arthrospira sp. This sequence was recovered from an Arthrospira culture whose the medium composition was far from the common standards (see text). 
have been recognized (Tomaselli, 1997). By total DNA restriction profile analyses of different strains of two putative species (Arthrospira platensis and Arthrospira maxima), Viti et al. (1997) were able to recognize two clusters corresponding to the putative morphological species. In contrast, using restriction profiles of the ribosomal ITS region, Scheldeman et al. (1999) divided 51 strains of Arthrospira (comprising several putative species) into two clusters unrelated in their morphology, species denomination or geographical origin.

Preliminary data (randomly amplified polymorphic DNA and total DNA restriction profiles, data not shown) have shown that the genetic background of Arthrospira is not correlated to morphological traits. For instance, strains with different morphology (spirals or rods) may have close DNA profiles, whereas strains with identical morphology may have divergent profiles. To determine the phyletic relationships between morphologically different Arthrospira strains, a region of the phycocyanin locus, namely the $c p c B-$ $c p c A$ spacer, has been sequenced because its nucleotide substitution rate is potentially higher than that of the widely used 16S rDNA sequence (Nelissen et al., 1996; Nübel et al., 1997; Ishida et al., 1997; Lyra et al., 2001; Barker et al., 2000a, b; Tillett et al., 2001; Robertson et al., 2001). Other cyanobacteria strains were used for comparison; the sequences of these were collected from DNA databases or produced during this work. The relationships between Arthrospira and Lyngbya (Guglielmi et al., 1993) and the lack of relations between Arthrospira and Spirulina are confirmed. A relationship between Planktothrix and Arthrospira is suggested. The available Arthrospira strains are divided into three groups. However, the $c p c B-c p c A$ data indicate exchange of genetic material between strains, making phylogenetic hypotheses impossible to establish. The intragenic recombination observed at this locus (and probably at others) would explain the discrepancies observed between morphological data and sequence data.

\section{METHODS}

Strains. Table 1 gives the list of Arthrospira strains studied, with their origin, culture history and the corresponding DNA database accession number of the $c p c B-c p c A$ locus. Data on the non-Arthrospira strains used in this work are also included.

DNA extraction, amplification and sequencing. Fresh or dry bacterial pellets were extracted following the method of Neilan et al. (1995) using lysozyme and proteinase K. The $c p c B-c p c A$ spacer was amplified using primers located within the coding region of $c p c B$ and $c p c A$, respectively. The forward primer was PC $\beta \mathrm{F}$ (Neilan et al., 1995). The reverse primer (5'-CCAGTTCCACCAGCAATCAG) was modified from the primer $\mathrm{PC} \alpha \mathrm{R}$ (Neilan et al., 1995) to match with the unpublished available sequence of $A$. platensis (accession no. Y09074). The amplified fragments (annealing temperature $50{ }^{\circ} \mathrm{C}$ ) were directly sequenced using the forward and reverse primers with the BigDye Terminator Cycle Sequencing kit and the 373 ABI sequencer (Perkin-Elmer).

Phylogenetic analysis. An overview of the phylogenetic position of Arthrospira in cyanobacteria was created by comparing the sequences of the Arthrospira cpcB-cpcA spacer to corresponding cyanobacterial sequences available in the databases and sequences obtained in this work from Spirulina major PCC $6313^{\mathrm{T}}$, Oscillatoria acuminata PCC $6304^{\mathrm{T}}$, Oscillatoria sancta $\mathrm{PCC} 7515^{\mathrm{T}}$ and Lyngbya aestuarii PCC $7419^{\mathrm{T}}$. The outgroup comprises the $c p c B-c p c A$ locus of three alga plastids: Cyanidium caldarium (S77125), $A g$ laothamnion neglectum (Z11906) and Rhodella violacea (Z48165). As the spacer was very variable, alignment of this region was impossible for most of these taxa (except $L$. aestuarii PCC $6313^{\mathrm{T}}$ ). Thus, phylogenetic analysis of this matrix was performed with the aligned coding regions only. On the other hand, the analyses of strains of Arthrospira were done with both the coding sequences and the spacer. Phylogenetic trees were obtained with PAUP 3.1 (parsimony analysis; Swofford, 1993) using a heuristic search with 10 replications of RANDOM stepwise additions of sequences, the TBR branch swapping and MULTPARS options in effect. Support of the clades was calculated with bootstrap analyses of 1000 replicates and TBR branch swapping.

Likelihood analysis of recombination. Using the program LARD as described by Holmes et al. (1999), the likelihood of the null hypothesis, $\mathrm{H} 0$, that there has been no recombination event at the $c p c B-c p c A$ locus and the likelihood, $\mathrm{H} 1$, that there has been a recombination event, were assessed from a simple unrooted tree of three sequences (Paracas P2, Maxima and $\mathrm{Bu} 1$, each belonging to the three putative classes of recombinants). To assess whether $\mathrm{H} 1$ is a significantly better fit to the data (i.e. that the likelihood ratio of $\mathrm{H} 1$ to $\mathrm{H} 0$ is greater than would be expected by chance), 500 sequence datasets were simulated using the program SEQ-GEN (Rambaut \& Grassly, 1997) under the maximumlikelihood H0 model and reanalysed using LARD.

\section{RESULTS AND DISCUSSION}

\section{Structure of the $c p c B-c p c A$ locus and phylogenetic implications}

Sequences obtained from the amplified fragments of the genus Arthrospira and L. aestuarii PCC $7319^{\mathrm{T}}$ comprised the last $255 \mathrm{nt}$ of $c p c B$, a $111 \mathrm{nt}$ spacer and the first $304 \mathrm{nt}$ of $c p c A$. For the other cyanobacteria, the size of the spacer was highly variable. A codon insertion was observed downstream of the start codon of cpcA in Fischerella sp., Anabaena sp. PCC 7120, Chroococcus dispersus, Nodularia spumigena and two strains of Synechococcus sp. (PCC 7942 and PCC 6301). A two-codon insertion was present in $c p c B$ of Microcystis aeruginosa.

The consensus tree of the four most parsimonious trees obtained (with all cyanobacterial taxa available and with the partial $c p c B$ and $c p c A$ coding sequences only) is shown in Fig. 1. The four most parsimonious trees are 2079 steps long and have a consistency index of $0.36(0.34$ excluding uninformative sites) and a retention index of 0.57 , suggesting that the coding sequence of this locus comprises a large number of homoplasies (reversions, parallelisms). Of the $23 \mathrm{Arth}$ rospira strains studied, one strain (Sun), unrelated to the other Arthrospira accessions, formed a clade with four of the five Synechococcus strains analysed. The data also indicate a close phylogenetic relationship 


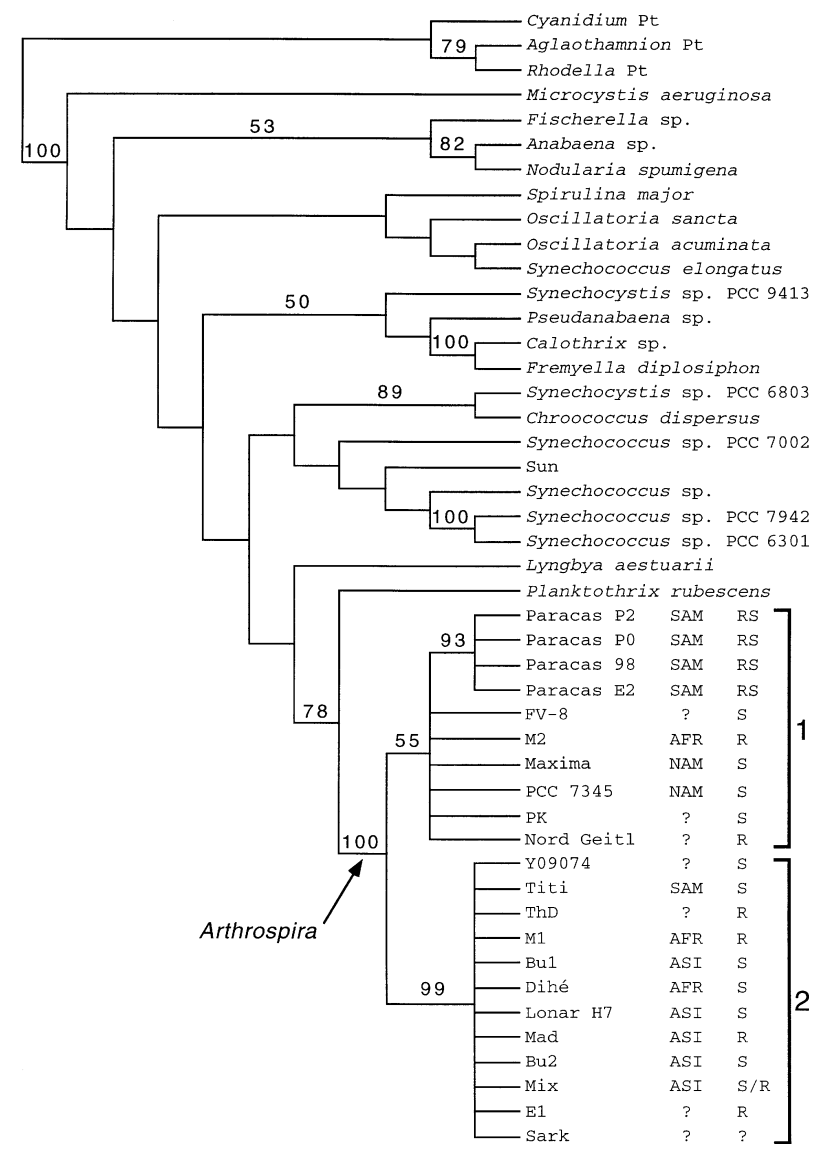

Fig. 1. Strict consensus tree of the four most parsimonious trees obtained from analysis of parts of the $\angle P C B$ and $c p c A$ coding sequences only. The outgroup comprises three algae platid $(\mathrm{Pt})$ sequences. Bootstrap values are indicated on the branches. The geographical origin of the Arthrospira strains are indicated by ASI (Asia), NAM (North America), SAM (South America) and AFR (Africa). The morphological aspect of strains is indicated by $R$ (rod), S (spiral) and RS (relaxed spiral).

between Arthrospira and Planktothrix (Oscillatoria) rubescens (Anagnostidis \& Komarek, 1988), as suggested from 16S rDNA data (Wilmotte, 1994; Nelissen et al., 1996). As already shown from 16S rDNA data (Guglielmi et al., 1993; Nelissen et al., 1996; Ishida et al., 1997), L. aestuarii PCC $7419^{\mathrm{T}}$ is also closely related to Arthrospira and is a sister to the clade Planktothrix/Arthrospira. As it is now widely accepted (Guglielmi et al., 1993), Spirulina major PCC $6313^{\mathrm{T}}$ is well distinct and relatively distant from Arthrospira. Results indicate that several genera are para- or polyphyletic: Synechocystis, Synechococcus and Oscillatoria. This is in accordance with $16 \mathrm{~S}$ rDNA data showing that several genera comprise unrelated strains (Nelissen et al., 1996; Ishida et al., 1997).

Regarding the general phylogenetic implications inferred by this DNA fragment in cyanobacteria, definitive conclusions must not be drawn because sampling in this analysis is low, the analysis is based on only one DNA sequence and high homoplasy is found

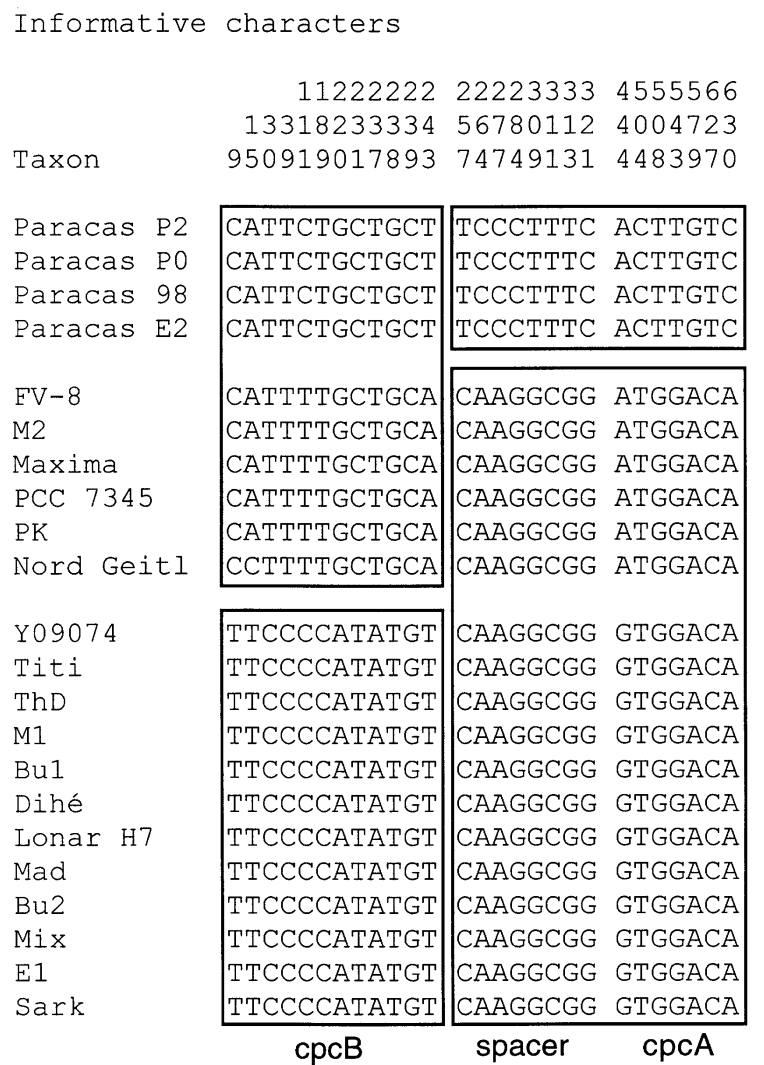

Fig. 2. Mosaic distribution of the variable sites at the $c p c B-c p c B$ locus of Arthrospira. To make the observation easier, the strains are classified according to the clusters of Fig. 1. Numbers above the alignment indicate the nucleotide position of the informative sites. Blocks of orthologous sequences are boxed.

in this DNA fragment. However, 16S rDNA data and $c p c B-c p c A$ data are often in agreement. As others have suggested from $16 \mathrm{~S}$ rDNA data, $c p c B-c p c A$ data also indicate that several taxa are genetically heterogeneous and that the taxonomy of cyanobacteria has to be reconsidered (Ishida et al., 1997; Guglielmi et al., 1993; Nelissen et al., 1996).

The phylogenetic structure of the genus Arthrospira was studied using both the coding and non-coding sequences. The matrix of the 22 Arthrospira strains (excluding the unrelated strain Sun) comprises 670 sites, 34 of them are variable and 27 are informative. The consistency index of the unrooted most parsimonious trees obtained using this matrix is equal to $1 \cdot 0$, suggesting no homoplasy. Fourteen of the 27 informative sites define an internal branch separating the group of the four strains of Paracas (Peru) from all other strains.

\section{Evidence of recombination in the $c p c B-c p c A$ locus of Arthrospira}

The informative sites of the $c p c B-c p c A$ DNA matrix of Arthrospira (with the taxa arranged according to the results of Fig. 1) are shown in Fig. 2. The mosaic 


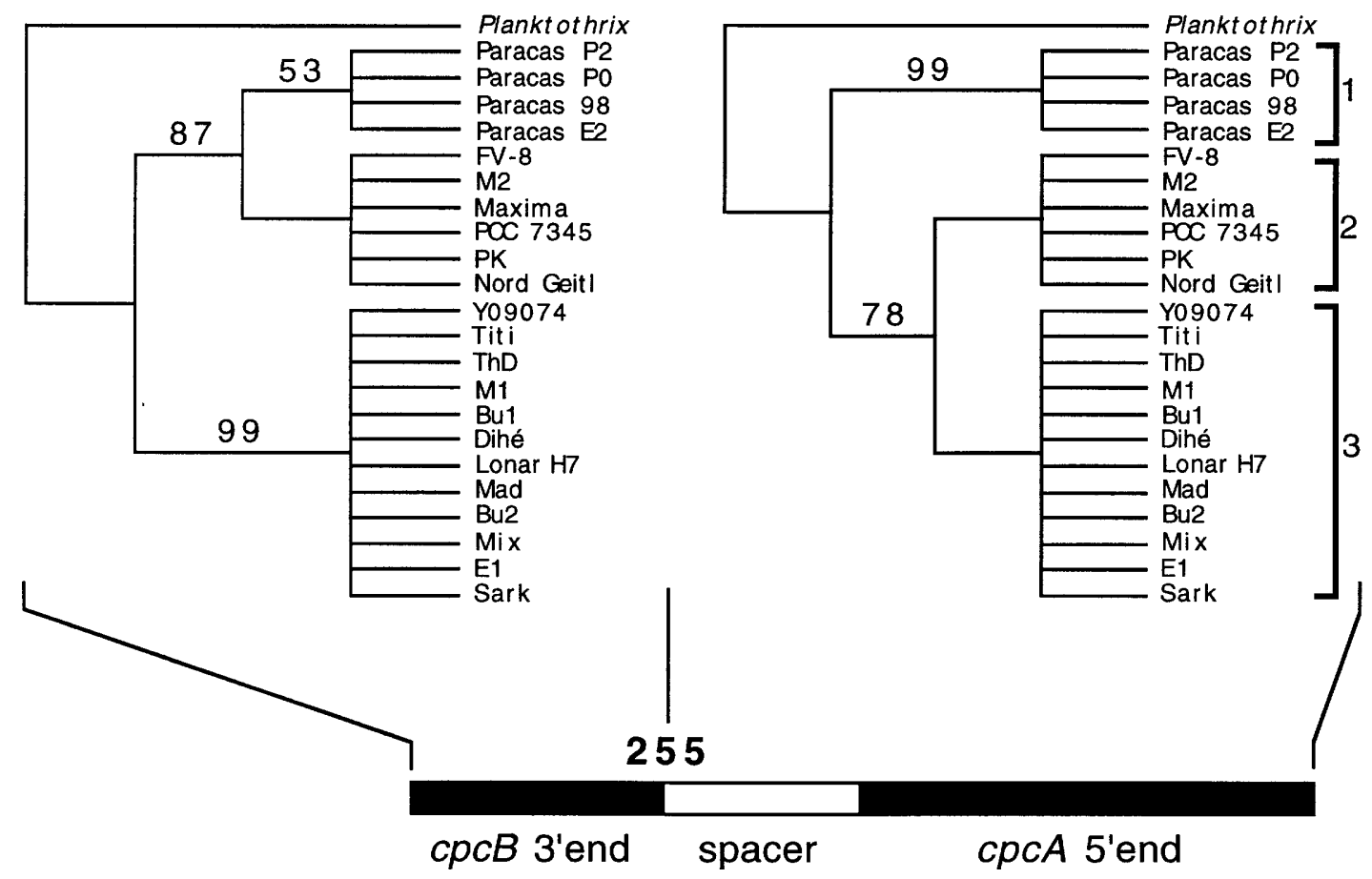

Fig. 3. Arthrospira phylogenies resulting from positions 1-255 ( $c p c B)$ and 256-670 (the spacer and $c p c A)$. Bootstrap values are indicated on the branches.

distribution of the substitutions suggests recombination events at this phycocyanin locus. A first block comprises positions $1-255$ (the $3^{\prime}$ end of the $c p c B$ translated sequence). A second block comprises positions 256-670 (the $c p c B-c p c A$ spacer and the 5' end of the $c p c A$ translated sequence). Fig. 3 shows the trees obtained with positions $1-255$ and 256-670, respectively. The first block clearly differentiates clades 1 and 2 as defined in Fig. 1. On the other hand, the substitutions of the second block do not separate clades 1 and 2, but differentiate the Paracas clade from all other strains. This is reminiscent of the mosaic structure of the distribution of informative sites observed in the rbcLX gene of Nostoc (Rudi et al., 1998). In Arthrospira, the phycocyanin locus also indicates intragenic recombination and suggests exchanges of genetic material between strains. Genetic exchanges have also been postulated in Nodularia (Barker et al., 2000a).

The LARD maximum-likelihood method (Holmes et al., 1999) was applied to find the breakpoint in the alignment which gave the highest likelihood under an evolutionary model incorporating recombination. This point was located after position 244, in agreement with Fig. 2. The likelihood ratio of H1 (recombination after position 244) to $\mathrm{H} 0$ (no recombination) was found to be 15.69. Monte Carlo simulation using SEQGEN (Rambaut \& Grassly, 1997) indicates that this ratio was significantly greater than for the 500 simulated datasets (mean of $4 \cdot 18$, maximum of 11.07). Thus, the Arthrospira tree topology does not reflect a true cladogenesis because of horizontal transfers. There is no correlation of the DNA matrix with the geographical origin or the morphology (rod or spirals), except for strains of the Paracas clade, which are characterized by a particular morphology (relaxed spirals; see micrographs in supplementary data in IJSEM, http://ijs.sgmjournals.org).

In nature, bacteria are living in local communities continuously exchanging biochemicals, such as nutritional factors, and genetic material, such as replicons, e.g. plasmids and prophages (Mathieu \& Sonea, 1996; Rudi et al., 1998). Thus, natural or cultured conditions offer totally different opportunities for evolution to bacteria. This could explain the discrepancies frequently observed between natural and cultivated cyanobacteria (Palinska et al., 1996). Ten years ago, Komarek \& Anagnostidis (1989) estimated that the features of more than $50 \%$ strains in collections do not correspond to the diagnoses of the taxa to which they are assigned. Are natural exchanges of genetic material between related or more distant taxa responsible for these observed discrepancies?

Several mechanisms have been proposed for the exchange of genetic material between strains by homologous recombinations as a consequence of conjugation, transduction by bacteriophages and occasional natural competence. Ecological, physiological and genetic mechanisms of natural exchanges of genetic material between bacteria are proposed (Lorenz \& Wackernagel, 1994; Syvanen, 1994). Some of these mechanisms might involve long-distance exchanges. 
Several observations indicate that exchange of genetic material is usual in (cyano)bacteria (Lawrence \& Ochman, 1998; Ueda et al., 1999; Rudi \& Jakobsen, 1999; Barker et al., 2000a). It is even proposed that such mechanisms are predominant in bacterial evolution and could explain the homogeneity of morphological characters and the observed morphological stasis for more than two billion years (Rudi et al., 1998). These observations make the use of DNA sequences questionable in a phylogenetic perspective, at least for phyletically related strains readily susceptible to homologous recombinations (Syvanen, 1987; Lawrence \& Roth, 1996; Lawrence, 1999; Young, 2001). In the case of Arthrospira, this would explain the discrepancies observed between morphological data (for instance rods or spirals) and sequence data, because of the comparison of paralogous DNA sequences. As the variations observed in this DNA fragment are not the result of an historical cladogenesis, a correlation between the geographical origin and the genetic clusters is not observed.

\section{The $c p c B-c p c A$ locus as a tool for identification of Arthrospira strains}

Based on the $c p c B-c p c A$ fragment, a phylogeny reflecting historical cladogenesis of the genus Arthrospira is not possible because this locus is subject to intragenic recombination. Consequently, the topology of the Arthrospira tree is the result of the comparison of historically unrelated DNA sequences. The fact that substitutions are transmitted in block explains a consistency index of the $c p c B-c p c A$-based tree of Arthrospira equal to $1 \cdot 0$.

The $c p c B-c p c A$ locus of the phycocyanin operon comprises moderately variable regions (both the $c p c B$ and $c p c A$ coding regions) and a highly variable region (the non-coding spacer between the coding regions). Thus, the coding regions can be used for comparisons with other genera of cyanobacteria. Excluding one strain (Sun), the Arthrospira strains available for this study form a strongly sustained monophyletic group. On the other hand, the spacer region is so variable in size and sequence that it allows strict differentiation of the genus Arthrospira from other cyanobacteria. As an illustration, the unrelated strain Sun, from Maduraï (India), was readily identified as non-Arthrospira. In retrospect, it was observed that this strain does not grow on the standard Arthrospira medium (Zarrouk, 1966) and is morphologically distinct. This easily noticed error demonstrates that this DNA fragment is suitable for an easy identification of the genus Arthrospira and probably other genera. In fact, the $c p c B-c p c A$ spacer is so variable that alignment is impossible between most of the genera and such a DNA fragment isolated from a particular strain is readily identifiable by comparison with data in a DNA bank.

Even if it is suspected of intragenic recombination, this DNA fragment allows clustering in Arthrospira. Fig. 3 shows that the genus comprises three clusters, the hierarchy of them being unknown, because of suggested horizontal transfer. The first cluster is represented by the Paracas lineage only and has a specific morphology and a restricted geographical origin. The second lineage comprises Fv-8, M2, Maxima, $A$. platensis PCC $7345^{\mathrm{T}}$, PK and Nord Geitl. The third lineage comprises Y09074, Titi, ThD, M1, Bu1, Dihé, Lonar H7, Mad, Bu2, Mix, E1 and Sark. The last two lineages have no correlation with morphology (rods/spirals) or geography. Similarly, in a study based on amplified rDNA restriction analysis (Scheldeman et al., 1999), Arthrospira is divided into two clusters that have no clear relationships with geographic origin and morphology. However, a comparison with their work is difficult because most strains used cannot be related with those analysed here. From the few identifiable strains, it is observed that Titi and Lonar cluster together and that A. platensis PCC $7345^{\mathrm{T}}$ is related to the other cluster, as in this study. However, in contradiction with the results reported here, their Maxima strain did not cluster with $A$. platensis PCC $7345^{\mathrm{T}}$.

In conclusion, the results demonstrate convincingly several points concerning the genus Arthrospira: (1) horizontal genetic transfers are suggested between the Arthrospira lineage; (2) the genus Arthrospira is monophyletic; (3) Arthrospira strains cannot be grouped according to their geographic origin; (4) Arthrospira strains cannot be grouped according to morphology, except for the 'relaxed spiral' type, which seems limited to strains originating from the Paracas region (Peru); and (5) because of very specific growing conditions (particularly high $\mathrm{pH}$ ), dense cultures of Arthrospira seems to exclude contamination with other cyanobacteria and an eventual accidental contamination can readily be detected by the analysis of the $c p c B-c p c A$ locus.

\section{ACKNOWLEDGEMENTS}

We thank Gisèle Vuille-dit-Bille for technical assistance, the providers of Arthrospira strains listed in Table 1 and Antenna Technologie for funding.

\section{REFERENCES}

Anagnostidis, K. \& Komarek, J. (1988). Modern approach to the classification system of cyanophytes. 3-Osillatoriales. Arch Hydrobiol Suppl 80, 327-472.

Barker, G. L., Handley, B. A., Vacharapiyasophon, P., Stevens, J. R. \& Hayes, P. K. (2000a). Allele-specific PCR shows that genetic exchange occurs among genetically diverse Nodularia (cyanobacteria) filaments in the Baltic Sea. Microbiology 146, 2865-2875.

Barker, G. L. A., Konopka, A., Handley, B. A. \& Hayes, P. K. (2000b). Genetic variation in Aphaizomenon (cyanobacteria) colonies from the Baltic Sea and North America. J Phycol 36, 947-950.

Belay, A., Ota, Y., Miyakawa, K. \& Shimamatsu, H. (1993). Current knowledge on the potential health benefits of Spirulina. J Appl Phycol5, 235-241.

Ciferri, O. \& Tiboni, O. (1985). The biochemistry and industrial potential of Spirulina. Annu Rev Microbiol 39, 503-526. 
Fox, R. D. (1996). Spirulina: Production and Potential. Aix-enProvence: Edisud.

Geitler, L. (1932). Cyanophyceae. In Kryptogamen-Flora von Deitschland, Osterreich und der Schweiz, vol. 14. Edited by L. Rabenhorst. Leipzig: Akad. Verlagsgesellschaft.

Guglielmi, G., Rippka, R. \& Tandeau de Marsac, N. (1993). Main properties that justify the different taxonomic position of Spirulina spp. and Arthrospira spp. among cyanobacteria. Bull Inst Oceanogr Monaco 12, 13-23.

Holmes, E. C., Worobey, M. \& Rambaut, A. (1999). Phylogenetic evidence for recombination in dengue virus. Mol Biol Evol 16, 405-409.

Ishida, T., Yokota, A. \& Sugiyama, J. (1997). Phylogenetic relationships of filamentous cyanobacterial taxa inferred from 16S rRNA sequence divergence. J Gen Appl Microbiol 43, 237-241.

Komarek, J. \& Anagnostidis, K. (1989). Modern approach to the classification system of cyanophytes. 4-Nostocales. Arch Hydrobiol Suppl 82, 247-345.

Lawrence, J. G. (1999). Gene transfer, speciation, and the evolution of bacterial genomes. Curr Opin Microbiol 2, 519-523.

Lawrence, J. G. \& Ochman, H. (1998). Molecular archaeology of the Escherichia coli genome. Proc Natl Acad Sci U S A 95, 9413-9417.

Lawrence, J. G. \& Roth, J. R. (1996). Selfish operons: horizontal transfer may drive the evolution of gene clusters. Genetics 143, 1843-1860.

Lorenz, M. G. \& Wackernagel, W. (1994). Bacterial gene transfer by natural genetic transformation in the environment. Microbiol Rev 58, 563-602.

Lyra, C., Suomalainen, S., Gugger, M., Vezie, C., Sundman, P., Paulin, L. \& Sivonen, K. (2001). Molecular characterization of planktic cyanobacteria of Anabaena, Aphanizomenon, Microcystis and Planktothrix genera. Int J Syst Evol Microbiol 51, 513-526.

Mathieu, L. G. \& Sonea, S. (1996). Review of the unique mode of evolution of bacteria: an opinion. Symbiosis 21, 199-207.

Neilan, B. A., Jacobs, D. \& Goodman, A. E. (1995). Genetic diversity and phylogeny of toxic cyanobacteria determined by DNA polymorphisms within the phycocyanin locus. Appl Environ Microbiol 61, 3875-3883.

Nelissen, B., Wilmotte, A., Neefs, J.-M. \& De Wachter, R. (1994). Phylogenetic relationships among filamentous helical Cyanobacteria investigated on the basis of $16 \mathrm{~S}$ ribosomal RNA gene sequence analysis. Syst Appl Microbiol 17, 206-210.

Nelissen, B., De Baere, R., Wilmotte, A. \& De Wachter, R. (1996). Phylogenetic relationships of nonaxenic filamentous cyanobacterial strains based on 16S rRNA sequence analysis. J Mol Evol 42, 194-200.

Nübel, U., Garcia-Pichel, F. \& Muyzer, G. (1997). PCR primers to amplify 16S rRNA genes from cyanobacteria. Appl Environ Microbiol 63, 3327-3332.

Palinska, K. A., Liesack, W., Rhiel, E. \& Krumbein, W. E. (1996). Phenotype variability of identical genotypes: the need for a combined approach in cyanobacterial taxonomy demonstrated on Merismopedialike isolates. Arch Microbiol 166, 224-233.
Rambaut, A. \& Grassly, N. C. (1997). SEQ-GEN: an application for the Monte Carlo simulation of DNA sequence evolution along phylogenetic trees. Comput Appl Biosci 13, 235-238.

Robertson, B. R., Tezuka, N. \& Watanabe, M. M. (2001). Phylogenetic analyses of Synechococcus strains (cyanobacteria) using sequences of $16 \mathrm{~S}$ rDNA and part of the phycocyanin operon reveal multiple evolutionary lines and reflect phycobilin content. Int $J$ Syst Evol Microbiol 51, 861-871.

Rudi, K. \& Jakobsen, K. S. (1999). Complex evolutionary patterns of tRNA UAA-Leu group I introns in the cyanobacterial radiation. $J$ Bacteriol 181, 3445-3451.

Rudi, K., Skulberg, O. M. \& Jakobsen, K. S. (1998). Evolution of cyanobacteria by exchange of genetic material among phyletically related strains. J Bacteriol 180, 3453-3461.

Scheldeman, P., Baurain, D., Bouhy, R., Scott, M., Mühling, M., Whitton, B. A., Belay, A. \& Wilmotte, A. (1999). Arthrospira ('Spirulina') strains from four continents are resolved into only two clusters, based on amplified ribosomal DNA restriction analysis of the internally transcribed spacer. FEMS Microbiol Lett 172, 213-222.

Swofford, D. L. (1993). PAUP : phylogenetic analysis using parsimony, version 3.1.1. Illinois Natural History Survey, Champaign, IL, USA.

Syvanen, M. (1987). Molecular clocks and evolutionary relationships: possible distortions due to horizontal gene flow. J Mol Evol 26, 16-23.

Syvanen, M. (1994). Horizontal gene transfer: evidence and possible consequences, Annu Rev Genet 28, 237-261.

Tillett, D., Parker, D. L. \& Neilan, B. A. (2001). Detection of toxigenicity by a probe for the microcystin synthetase A gene ( $m c y \mathrm{~A})$ of the cyanobacterial genus Microcystis: comparison of toxicities with $16 \mathrm{~S}$ rRNA and phycocyanin operon (phycocyanin intergenic spacer) phylogenies. Appl Environ Microbiol 67, 2810-2818.

Tomaselli, L. (1997). Morphology, ultrastructure and taxonomy of Arthrospira (Spirulina) maxima and Arthrospira (Spirulina platensis). In Spirulina platensis Arthrospira: Physiology, Cell Biology and Biotechnology, pp. 1-15. Edited by A. Vonshak. London: Taylor and Francis.

Ueda, K., Seki, T., Kudo, T., Yoshida, T. \& Kataoka, M. (1999). Two distinct mechanisms cause heterogeneity of 16S rRNA. J Bacteriol 181, 78-82.

Viti, C., Ventura, S., Lotti, F., Capolino, E., Tomaselli, L. \& Giovannetti, L. (1997). Genotypic diversity and typing of cyanobacterial strains of the genus Arthrospira by very sensitive total DNA restriction profile analysis. Res Microbiol 148, 605-611.

Wilmotte, A. (1994). Molecular evolution and taxonomy of the cyanobacteria. In The Molecular Biology of Cyanobacteria, pp. 1-25. Edited by A. B. Bryant. Dordrecht: Kluwer.

Young, J. M. (2001). Implications of alternative classifications and horizontal gene transfer for bacterial taxonomy. Int J Syst Evol Microbiol 51, 945-953.

Zarrouk, C. (1966). Contribution à l'étude d'une cyanophycée: influence de divers facteurs physiques et chimiques sur la croissance et la photosynthèse de Spirulina maxima (Setch et Gardner) Geitler. Thesis, Faculté des Sciences de l'Université de Paris. 